\title{
Kyoto Protocol implementation in Serbia as precognition of sustainable energetic and economic development
}

\author{
Mirjana Golusin*, Olja Munitlak Ivanovic \\ Educons University, Vojvode Putnika bb, Sremska Kamenica, 21202 Serbia
}

\section{A R T I C L E I N F O}

\section{Article history:}

Received 22 November 2010

Accepted 7 February 2011

Available online 5 March 2011

\section{Keywords:}

Energy policy

Strategic planning

Carbon credits

\begin{abstract}
A B S T R A C T
The paper gives reasons for low energy efficiency typical of the Serbian economy, which is based on outdated and dirty technologies. The comparison of selected economic indicators and indicators of energy efficiency in both Serbia and the European Union points out the benefits of the Kyoto Protocol implementation due to the growth of competitiveness in the global market. Serbia has no obligation to reduce GHG emissions, the authors point to the proposals whose implementation along with the mechanisms of the Protocol can enable Serbia the access to markets that trade GHG emissions and the access to dedicated funds, self-financing or attracting foreign investments to raise energy efficiency, which will be accompanied by adequate economic benefits. A similar principle can be applied in all countries that are not obliged to reduce GHG emissions. The application of different mechanisms aiming to increase energy efficiency in Serbia, could contribute to the increase of GDP annual growth rate from $5 \%$ to $7 \%$, which cannot be achieved by any other economic instrument. Energy efficiency, which is actually a question of competitiveness of each economy, can finance itself through the mechanisms of the Kyoto Protocol by selling excess emissions resulting from improved energy efficiency.
\end{abstract}

(c) 2011 Elsevier Ltd. All rights reserved.

\section{Introduction}

Economic development is only part of the development of a country, for it is obvious that a more intensive economic growth is impossible without environmental protection and reproduction of the environment. Economic growth and development cannot be unlimited, because the production process cannot function independently of the ecological capacity of the living environment. Contemporary conditions of production in highly developed countries are characterized by a compromise (trade off) between the quality of the environment and the economic development of the country. The economic system that does not value natural resources, and stimulates the economic growth regardless of the consequences on the limited resources is not sustainable in the long run. Basically, the entire economic system is to act in accordance with the mature ecological system. Both systems are characterized by cyclicity. An optimal economic system needs to be more productive but also to remove unwanted residuals-waste materials and a surplus of used or emitted energy. As a matter of fact, the Kyoto Protocol mechanisms allow their control and gradual elimination.

\footnotetext{
* Corresponding author. Tel.: +38164205 7261 .

E-mail addresses: mirjanagolusin@sbb.rs (M. Golusin), oljaivanovic@eunet.rs (O. Munitlak Ivanovic).
}

The Kyoto Protocol was adopted as a protocol along with the Convention on Climate Change (UNFCCC) in 1997. The main objective of the Convention is to achieve "the stabilization of the concentration of gases producing the greenhouse effect at a level that would not lead to dangerous anthropogenic impacts on the climate system" and thus raise the energy efficiency through international collaboration of developed and underdeveloped countries signatories to the Protocol. This would provide the technology transfer, increase of energy efficiency and flow of financial resources into developing countries (Kyoto protocol, 2005).

Energy efficiency involves rational and effective use of natural resources, replacement of imported fuel with domestic energy sources, use of renewable and alternative energy sources, and increase of energy efficiency in the production and final consumption of energy. The direct link between the implementation of the Protocol mechanisms and characteristics of high energy efficiency is evident. The relationship between the consumed energy and economic results is considered to be one of the main indicators of energy intensity of the economy. Under the energy intensity coefficient is meant the amount of energy used for the creation of a certain value of GDP, mostly 1000 USD, at constant prices in 1995 that is regarded as base year after the methodology used by the International Energy Agency (IEA). Energy efficiency is a value expressed in constant dollars and created by using the energy of 1 ton of oil equivalent (toe). 
The year 1990 was selected as the basis for assessing and measuring the annual emissions of all countries but each country separately negotiates about its obligation to reduce GHG emissions. The percentage of reduction is at least $5 \%$ but the old EU member states committed themselves to reduce the emission by $8 \%$ and Japan by $6 \%$ in comparison to, while Russia and Ukraine pledged to maintain 1990 levels[1].

The EU had begun to implement measures to reduce GHG emissions even before the official entry into force of the Protocol, which gave very good results regarding the growth of energy efficiency. These positive effects are numerically expressed in the paper section related to the research of the EU energy efficiency indicators. Until now, 175 countries accepted it including the countries of Southeastern Europe.

The Republic of Serbia signed the Convention on Climate Change in June 2001. In September Serbia ratified the Kyoto Protocol and signed it in January 2008. The aspiration to join the EU and the stabilization and association processes impose an obligation to Serbia to apply European standards concerning the living environment. Even $30 \%$ of legislation that needs to be adapted to EU standards is related to environmental protection. The ratification and signing of this document do not oblige Serbia, but it provides the opportunity to contribute to the reduction of GHG emissions, increase energy efficiency, gradually implement the principles of sustainable economic development, and reduce the local pollution of the environment (Golušin et al., 2009). In terms of collecting data on the situation in the field of energy, in 2001 was established the National Energy Efficiency Program. The Energy Sector Development Strategy in Serbia until 2010, which was formulated in the Economic Development Strategy of Serbia until 2010, set the goals that are the subject of the following discussion, but with a small probability of realization due to global economic disorders.

\section{Kyoto Protocol effect on economic growth and energy efficiency}

International mechanisms allow a transfer of programs among the countries that are parties to the Protocol in the period 20082012. As limit costs of reducing pollution are in most cases much higher in industrialized countries than in developing countries, the Protocol provides a mechanism of international trade transferable licenses for glasshouse-effect gas emissions ("carbon market"). The market primarily deals with the trade carbon, although five other gases causing the greenhouse effect may be subject to sale. Financially speaking, it is more justified to reduce emissions in countries whose production processes are outdated and inefficient than in developed countries where the reduction of emissions would require more expensive and more advanced technologies than the ones already applied. Each of the three new mechanisms gives the opportunity for different types of exchange between groups of countries:

1. Joint Implementation (JI)-Countries from Annex B of the Protocol may transfer to or get from any other party "emission reduction units" that have emerged through the emission reduction during the investment in anther industrialized country.

2. Clean Development Mechanism (CDM)-This mechanism allows emission reduction projects, supporting the sustainable development of developing countries, which is its important economic role. In this financially favorable way, host countries not only meet obligations regarding the Protocol but also the achieved results of emission reductions are calculated as verified emission reductions (Emission Reduction Certified-CER) that have their value in the market.

3. International Emission Trading (IET) relates to the aforementioned flexible mechanism of "carbon market". Member states listed in Annex B of the Protocol may trade "Assigned Amount Units" (AAUs) for the purpose of fulfilling their obligations.. Developed countries obliged to reduce GHG emissions can instead buy part of the emission of countries or companies from Annex I whose emissions are below the approved level. Another way to acquire "emission credits" is to invest in projects for GHG reduction, i.e. in projects to improve energy efficiency in developing countries. The allocation of projects is not easy because the United Nations conduct detailed analyses of specific projects and their impact on emissions before the projects are approved.

From the clean development mechanism and international emissions trading, it is clear that the Kyoto Protocol cannot be viewed only as an instrument for achieving environmental goals but also the economic ones. The raising of energy efficiency is a goal that cannot be achieved only by ecological measures and protective environmental measures, but also by economic measures since the increase of energy efficiency requires large financial resources. They can be accumulated through the emission trade in the "Carbon Market", by investing in ventures that directly ("green technologies") or indirectly raise energy efficiency. In any case, the international exchange of knowledge, technology and know-how, investments and all other forms of international assistance and joint projects are a condition without which it cannot be expected that the developed or undeveloped countries will increase energy efficiency or reduce GHG emissions. An environmental problem that occurs at the local level usually has wider geographical or even global consequences (Gingrich et al., in press).

Due to the lack of financial means the countries not listed in Annex I-developing countries are not obliged to reduce their GHG emissions, for it is usually the only way to continue their economic growth and development. This again stresses the connection between environmental and economic problems. Very often environmental problems, such as reducing emissions or increasing energy efficiency cannot be solved without additional investments. Therefore, the clean development mechanism includes the implementation of projects for current or future reductions of GHG emissions. In this way a support is provided for the sustainable economic and environmental development of developing countries on one hand, and on the other hand, developed countries are allowed to keep their emissions and economic growth on the prescribed level. Serbia is a country that has no obligation to reduce GHG emissions.

A direct correlation is observed between the GDP growth and greenhouse gas emissions, i.e. low energy efficiency. Relatively speaking, the gas emission increases in case of lower national income, and then grows slightly slower; while in the mature stages of development begins to decline. The fall of GHG emissions and increase of energy efficiency is a consequence of the intensified use of the pollution reduction system and of the use of economic instruments, for the realization of which is required not only environmental awareness but higher income as well (Golušin and Munitlak Ivanović, 2009). The link between the pollution (environmental problem) and the social wealth (economic result) is reflected in the per capita income greater than 10 USD a day. Namely, an increase in daily income from less than 1 USD to 10 USD per capita also leads to growing of pollution levels, whereas by a further increase of the daily income from 10 USD to 100 USD per capita, the pollution is reduced. Fig. 1 shows the relationship 


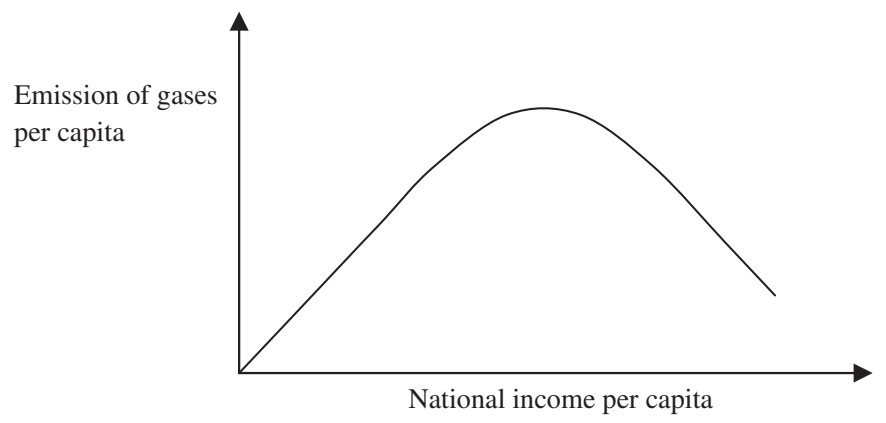

Fig. 1. Relationship between growth of national income per capita and emission of greenhouse gases-ecological costs per capita.

Source: Adapted after a group of authors, Encyclopedia, Environment and Sustainable Development, Ecolibri, Belgrade, 2003, p. 385.

between the growth of national income per capita and the emission of greenhouse gases.

\section{Effects of Kyoto Protocol implementation in Serbia}

\subsection{Effects on energy efficiency}

The using of the Kyoto Protocol mechanisms creates the conditions for improving the energy efficiency of Serbia, whose production is characterized by high energy inefficiency. Serbia is, when it comes to energy efficiency, in a situation that was similar in those of its neighboring countries until they in 2004 joined the European Union and accepted the EU directives related to the area. At present Serbia has the lowest level of energy efficiency in Europe. Since the Serbian national body for the implementation of clean development mechanism does not work, the sub-regional center for climate change for Southeastern Europe does not exist, and state representatives in the UN bodies responsible for the implementation of the Convention and the Protocol have not been elected, the analyses available publicly are incomplete and not quite accurate. Nevertheless, the analyses show that in Serbia the energy is not used rationally in comparison to the neighboring countries, and that the product is based on the technical minimum that modern technology and environmental protection allow.

The Energy Efficiency Agency was established only in 2004 and since then there has been a trend to achieve positive results and to take more care in this area. The continuation of the second phase to increase energy efficiency is scheduled for 2010. Consequently, projects worth 30 million USD co-financed with the World Bank loan have been started. International organizations like the World Bank have established special funds (carbon funds) in order to invest in projects to reduce GHG emissions in developing countries and to make a profit on this ground by trading with emission credits thus obtained. On this basis the project co-funded by the World Bank has been initiated. The Kyoto Protocol mechanism encourages developed countries to invest in developing countries that are parties to the Agreement through projects to reduce emissions.

Serbia has started to create the First national communication while the countries in the region are already preparing their second communications with the UN Commission (Kovačić, 2010). The First national communication includes risk assessment and definition of measures for adaptation to the changing climatic conditions, identification of sets of measures to mitigate climate changes and development of GHG emission inventory. Part of the report related to the risk assessment and definition of measures for adaptation to the changing climatic conditions assumes the application of climate scenarios and socioeconomic scenarios prior to the assessment of impact on various economic sectors. Based on the assessment of trends of climate changes in Serbia, it is necessary to conduct vulnerability assessment related to human health, water resources, forestry, agriculture and natural ecosystems.

\subsection{Economic effects}

So far, no institution has calculated how much climate changes cost Serbia. Analyses made in the Hydro-meteorological Institute of Serbia and the Serbian Environmental Protection Agency have shown that by the end of this century average air temperatures in the territory of Serbia could increase by $3-4{ }^{\circ} \mathrm{C}$ per year. Such a scenario would certainly have enormous negative consequences in all sectors, especially in the agricultural production. The rainfall reduction estimates of about $20 \%$, temperature growth and lack of irrigation systems would adversely affect the entire economy, because the income from agriculture is one of the main sources of growth of gross domestic product of Serbia. The direct link between climate changes that are the subject of the Kyoto Protocol and sustainable economic development is obvious (Mewton and Cacho, 2011).

The Kyoto Protocol should not be taken as a document that merely affects the environmental protection, but as an economic challenge and priority. By the international community Serbia is still considered to be a developing country, and international investments due to the implementation of the Kyoto Protocol could make a positive impact on the intensity of economic activities. The access to the international market of GHG emission could at an affordable price create necessary conditions for technological progress and long-term economic growth. Such investments would reduce the negative economic effects caused by low levels of energy efficiency and a high intensity of emissions of harmful gases in production processes (Munitlak Ivanović et al., 2009). The implementation of well-designed environmental policy in Serbia may give favorable economic results. It is estimated that only in the energy and mining sector in Serbia it is necessary to invest more than $€ 1.2$ billion to protect the natural environment and harmonize the current legislation with the EU regulations. In order to apply the Kyoto Protocol, the Ministry of Environmental Protection has begun some of the necessary activities. The drawing up of the above-mentioned First National Communication is certainly the most significant development.

All countries from Annex I, including Serbia, on whose territories are implemented CDM projects, benefit from attracting foreign investments, record a growth in money transfers and have the opportunity of introducing technically advanced "green" technologies. Besides, these investments have positive consequences on the economy and ecology of host countries, because the imported technologies are progressive and more energy efficient. Particularly interesting is the option to sell CERs resulting from the realization of CDM projects. In this way, it is possible to finance environmentally friendly projects that are not financially attractive and profitable for foreign investors. Serbia could obtain carbon credits by realizing various projects:

- Energy supply from other energy sources (renewable energy, biomass for obtaining electricity and heat, increasing energy efficiency by replacing inefficient technologies with modern technologies, substitution of fuels, reducing transportation and distribution costs, etc.).

- Reduction of energy needs (home appliances substitution, use of energy efficient light bulbs, and improving of energy efficiency of existing appliances). 
- Forestation.

- Waste management (use of waste water, waste materials and methane emission from landfills) and

- Changes in the transport (change of fuel type - from petrol to gas, use of more efficient engines, change of transportation type - rail instead of air transport).

Additionally, there is a chance for achieving economic results through the sale of emission credits earned by reducing GHG emissions. To appear as a subject in the international carbon market, a country must ratify the Protocol. Although Serbia signed and ratified the Kyoto Protocol, it is necessary to implement appropriate mechanisms for the realization of such projects. In fact, a country like Serbia that is not listed in Annex I can invest individually in a project to reduce GHG emissions in its territory, and then sell emission credits obtained in the reduction of emissions in the international market. For these reasons, industrialized countries have developed their own regional GHG emissions trading mechanisms in order to remain competitive.

There would be no negative economic consequences for Serbia even if it became a part of Annex I, which now seems unlikely, as it would not be obliged to reduce GHG emissions. According to the evaluation of the Center for Advanced Economic Studies (CEVES) the level of emissions in Serbia is much lower in comparison to the level in 1990. This situation allows Serbia to trade "hot air" (the difference in the emission level from 1990 and current year) until it reaches the level of emissions from the base year of 1990. If Serbia was a member of Annex I, it could carry out projects to reduce GHG emission as part of the Mechanism for joint implementation of the Kyoto Protocol, which operates on the same principle as the Clean Development Mechanism, which is only available to countries in Annex I.

It is important to take into account the fact that in the modern global business environment carbon dioxide $\left(\mathrm{CO}_{2}\right)$ has become a commodity. $\mathrm{CO}_{2}$ can be a tradable item on international markets, and air pollution is the economic tool and not just the negative externality of a production process. In December 2008, the average price of futures contracts in the European market was about $€ 20$ per ton of $\mathrm{CO}_{2}$. The total monetary value of annual $\mathrm{CO}_{2}$ emissions in Serbia is around one billion Euros. If Serbia managed to reduce emissions to zero, on this basis it could earn a billion Euros a year on the international carbon market. The hypothetical example of the zero emission is an unrealistic goal, and only indicates that any emission reduction, improvement of energy efficiency or introduction of cleaner production processes represents a potential profit on the international market. Energy efficiency, which is the issue of competitiveness of each economy, can finance itself by selling the excess emissions resulting from improved energy efficiency due to the mechanism of the Kyoto Protocol.

In addition to high levels of emissions in the production, it should be pointed out that the electricity price in Serbia is very low. Actually, it is the lowest in Europe and Central Asia as a result of state price subsidies (Stambouli, in press). Low electricity prices do not motivate consumers to increase their energy efficiency (electricity saving, energy efficient windows, modern appliances that consume less electricity, central heating systems with self-regulation of energy consumption, etc.).

Bringing electricity prices to market levels is being postponed in the last few years. It is a measure of monetary policy that maintains the current rate of inflation and slows down its growth. As the price of energy sources is included in the cost of production and consumer goods, the increase of the price of any fuel starts the growth spiral of prices in all goods and services and discourages the inflow of foreign capital. As a result of low prices of energy sources, companies increase their revenue by increasing the production volume and sales without simultaneously reducing energy input costs or increasing energy efficiency. Due to the market effects, the prices of energy sources will inevitably begin to rise resulting in further lowering of competitiveness of Serbian companies at the international market, for it is burdened with additional low energy efficiency. However, the present low energy efficiency is a potential source of energy and a comparative economic advantage (Munitlak Ivanović, 2005).

\section{Research methodology}

The subject of the investigation is the analysis of the energy sector in Serbia as a country that can potentially enter the carbon market. The investigation includes several basic segments.

First, the primary analysis was carried out in the energy sector in Serbia, whose results show basic information on energy resources, manufacturing, technologies, and prices and consumption of energy sources.

In the next phase of the investigation the comparison of energy efficiency and energy supply in Serbia and the EU was conducted in order to survey the actual situation in the energy sector in Serbia. The subject of the analysis in this phase is energy efficiency measured by a variety of indicators that are presented, i.e. identifying the cause of these results based on the share of different forms of primary energy sources in Serbia and the EU. The numerical data presented in tables and figures are results of statistical analyses conducted by the International Energy Agency (IEA).

Based on the data on population and the amount of aggregate GDP, and seen through the purchasing power parity, energy production, net imports of energy sources, the emitted amount of dominant greenhouse gas- $\mathrm{CO}_{2}$ in the production of GDP, electric power consumption and $\mathrm{CO}_{2}$ emission, the comparison was carried out concerning general indicators of economic efficiency and energy efficiency of Serbia and the EU.

Next, relative indicators related to the energy efficiency of Serbia and the EU member states are given: the coefficient of energy intensity per capita, the coefficient of energy intensity in the production of 2000 USD, the coefficient of energy intensity of GDP production observed through purchasing power parity, the consumption of electricity per capita, the emission of $\mathrm{CO}_{2}$ in the production of a ton of oil equivalent $\left(10^{7} \mathrm{kcal}\right), \mathrm{CO}_{2}$ emissions per capita, $\mathrm{CO}_{2}$ emissions in the production of GDP, and $\mathrm{CO}_{2}$ emissions regarding GDP observed in the purchasing power parity.

The comparison referred to Serbia and the EU as a whole. Even before the official entry into force of the Protocol, the EU began to implement measures to help reduce greenhouse gases. The Union is viewed as a whole although it is quite certain that concrete individual results among all 27 member states vary. Moreover, all new EU members including Bulgaria and Romania had to ratify the Protocol as part of association preconditions. European countries outside the EU such as Macedonia (2004), Albania (2005), Montenegro and Croatia (2007) ratified the Protocol prior to Serbia, which did it. The reason for comparing the energy efficiency of Serbia and the EU as a whole is precisely the fact that they both signed and ratified the Kyoto Protocol. Serbia belongs to developing countries and has low energy efficiency; however, within the EU some of the new member states have similar economic characteristics and energy potentials, which make this comparison logical and justified.

\section{Research results}

\subsection{Serbian energy system}

As an introduction to the part dealing with the comparison of energy efficiency indicators in Serbia and the EU, herein are 
presented data that characterize the Serbian energy system describing the situation in it and pointing to its great energy inefficiency. Final electrical energy consumption related to the heating of private and office buildings is great and irrational due to the relationship between prices and costs. Namely, from social and monetary reasons, the prices of almost all energy sources and other fuels are low and do not cover production costs [9]:

- Serbia has scarce reserves of energy sources. Most of the reserves are lignite surface mines. Approximately $50 \%$ of the final energy consumption in Serbia is provided by importing oil and gas, despite the fact that about $95 \%$ of electricity is produced using domestic energy sources-lignite and hydro potential. Disregarding the energy consumption in transport, energy production in industry and for distant district heating is mainly based on imported liquid and gaseous fuels. Only about $20 \%$ of the required oil and gas is provided from domestic sources.

- The technology used in the production and use of energy is outdated and dirty "because it has not changed since the beginning of the 1980 s, which means that it is generally about three decades old. Considering the rapid development of science, and of fundamental and applied research in the technology domain, this period is extremely long.

- There have been no significant investments in the energy sector over the last $10-15$ years, so that a large number of facilities are fully depreciated and in bad condition, hence there is an urgent need to overhaul the existing equipment or purchase new one.

- The situation in the production of energy in industry and distant district heating of households is worse than in large thermal power plants.

- GHG emission control systems and emission standards in Serbia are far lower than the standards that characterize the environmental policy of the EU. This has resulted in serious ecological problems in ecosystems in the vicinity of thermal power plants, and industrial and distant district heating power stations.

- Electricity production, energy production in industry and distant district heating, transport and distribution of electricity, and final energy consumption are characterized by energy wasting.

- Although the GDP in comparison to 1990 decreased by 2.5 times, the electricity consumption per capita of $3400 \mathrm{kWh}$ a year is at the level of medium developed countries in Europe that have a much higher GDP.

- The consumption of electricity per year for the production value of GDP is $1700 \mathrm{kWh} / 1000 \mathrm{USD}$, which makes it the biggest in Europe.

- The total annual consumption of all forms of energy to produce the GDP worth 1000 USD is the biggest in Europe and equals 1100 toe/1000 USD, but the total consumption of 1500 toe/per capita per year is the lowest in Europe.

- Losses in the transmission and distribution of electricity are the highest in Europe, amounting to $19 \%$.

- The electricity price of about 2 USD cent/kWh is several times lower than in Europe; consequently, there is high electricity consumption in households. This consumption rose from 35\% to $55 \%$ of the total production, while due to the low volume of industrial production the consumption in industry decreased from $37 \%$ to $31 \%$.

The situation in the energy sector in Serbia is characterized by obsolete systems and energy inefficiency, high costs and irrational consumption. All this points to the need to consider the situation and solutions that exist in the EU, which would enable Serbia to use its privileged status of a country that does not have to reduce emissions of greenhouse gases and thus enter the market of carbon credits.

\subsection{Comparison of selected key energy indicators for Serbia and the EU}

Table 1 shows selected general indicators in 2009 concerning Serbia and the 27 member states of the EU.

The data given in table show that the EU population is about 67 times larger than Serbian. Accordingly, it is logical that the aggregate GDP is higher. However, the aggregate GDP is even about 943 times larger. Seen through the purchasing power parity that relationship is somewhat different, i.e. the GDP seen through purchasing power parity (PPP) is 203 times larger. Following the larger population and higher GDP, the total production of energy is higher (about 88 times). It points to a higher economic growth, economic prosperity and a higher level of production in the $27 \mathrm{EU}$ members. Logically, the net imports of Serbia, as a country with fewer people and less developed economy, are much smaller, even 162.55 times. It is also interesting that imports per capita (net imports/population) in Serbia and the EU are 0.82 and 1.93 , respectively, indicating that the EU is energy dependent on imports, although its energy production is about 88 times higher.

The emitted amount of $\mathrm{CO}_{2}$ in the $\mathrm{EU}$ for the production of one unit of GDP (TPES) in relation to the base year is about 111 times larger, but considering that the aggregate GDP with such a technology is even about 943 times larger, it is evident that the energy efficiency of the EU is at significantly higher levels than in Serbia. The emission of the same gas obtained in the combustion of petrol is only 78 times higher. Aggregately speaking, electricity consumption in the EU is about 103 times higher than in Serbia, but observed per capita (electricity consumption/population) the consumption in the EU and Serbia is 6:38 and 4:15, respectively, indicating the high consumption of electrical power per capita in the EU.

Table 2 also shows that observed through energy indicators (Compound Indicators) there is better use of energy and higher energy efficiency. Individual values of almost all energy indicators monitored in the EU are better in comparison to Serbia.

$\mathrm{CO}_{2}$ emission for the production of a unit of GDP per capita in Serbia is smaller and equals 2:14 (toe/capita), whereas in the EU it is 3:55 (toe/capita). The relation between the amount of emitted $\mathrm{CO}_{2}$ in the production of GDP unit and the produced GDP is 00:18 (toe/thousand 2000 USD) in the EU and 1.20 (toe/thousand 2000

Table 1

Selected 2007 key indicators for Serbia and European Union-27.

Source: http://www.iea.org/stats/indicators.asp? IEA Energy Statistics - Energy Indicators for European Union - 27 and Serbia, date of extraction: 24 April 2010, 21:51 CEST.

\begin{tabular}{|c|c|c|}
\hline Key Indicators & $\begin{array}{l}\text { Indicators for } \\
\text { Serbia }\end{array}$ & $\begin{array}{l}\text { Indicators for European } \\
\text { Union }-27\end{array}$ \\
\hline Population (million) & 7.39 & 495.95 \\
\hline GDP (billion 2000 USD) & 13.14 & $12,392.81$ \\
\hline $\begin{array}{l}\text { GDP (PPP) } \\
\text { (billion } 2000 \text { USD) }\end{array}$ & 48.37 & 9827.29 \\
\hline Energy production (Mtoe) & 9.75 & 860.59 \\
\hline Net imports (Mtoe) & 6.05 & 983.47 \\
\hline TPES (Mtoe) & 15.81 & 1758.85 \\
\hline $\begin{array}{l}\text { Electricity consumption }{ }^{\mathrm{a}} \\
\text { (TWh) }\end{array}$ & 30.67 & 3168.21 \\
\hline $\begin{array}{l}\mathrm{CO}_{2} \text { Emissions }{ }^{\mathrm{b}} \\
\left(\mathrm{Mt} \text { of } \mathrm{CO}_{2}\right)\end{array}$ & 49.71 & 3926.39 \\
\hline
\end{tabular}

a Gross production+imports - exports - transmission/distribution losses.

${ }^{\mathrm{b}} \mathrm{CO}_{2}$ Emissions from fuel combustion only. Emissions are calculated using IEA's energy balances and guidelines. 
Table 2

Selected 2007 Compound Indicators for Serbia and the EU -27.

Source: http://www.iea.org/stats/indicators.asp? IEA Energy Statistics - Energy Indicators for European Union - 27 and Serbia, date of extraction: 24 April 2010, 21:51 CEST.

\begin{tabular}{lll}
\hline Compound indicators & $\begin{array}{l}\text { Indicators for } \\
\text { Serbia }\end{array}$ & $\begin{array}{l}\text { Indicators for European } \\
\text { Union_-27 }\end{array}$ \\
\hline $\begin{array}{l}\text { TPES/population (toe/capita) } \\
\text { TPES/GDP (toe/thousand 2000 }\end{array}$ & 2.14 & 3.55 \\
$\quad 1.20$ & 0.18 \\
USD) & & \\
TPES/GDP (PPP) (toe/thousand & 0.33 & 0.14 \\
2000 USD) & & \\
Electricity consumption/ & 4153 & 6388 \\
$\quad$ population (kWh/capita) & 3.14 & 2.23 \\
$\mathrm{CO}_{2} / \mathrm{TPES}(\mathrm{t} \mathrm{CO} /$ toe) & 6.73 & 7.92 \\
$\mathrm{CO}_{2} /$ population (t CO$/$ capita) & 3.78 & 0.40 \\
$\mathrm{CO}_{2} / \mathrm{GDP}(\mathrm{kg} \mathrm{CO} / 2000 \mathrm{USD})$ & 1.03 & 0.32 \\
$\mathrm{CO}_{2} / \mathrm{GDP}(\mathrm{PPP})(\mathrm{kg} \mathrm{CO} / 2000 \mathrm{USD})$ &
\end{tabular}

USD) in Serbia, which tells a lot about the energy intensity of Serbian production that consumes more energy and yet has a lower GDP. If the same values are observed through the purchasing power parity in the same units (toe/thousand 2000 USD), the relations are similar since in the EU this indicator is 00:14 while in Serbia it is 0:33, which means that a greater part of the "consumer basket" in Serbia goes for this. Based on the data from Table 1 it is established that the energy consumption per capita in the EU is higher, which can also be seen from Table 2 . In fact, electricity consumption per capita monitored through Compound Indicators points to a higher value in the EU (6388 kWh/capita) compared to Serbia (4153 kWh/capita). The ratio $\mathrm{CO}_{2} / \mathrm{TPES}$ in the EU is $2: 23\left(\mathrm{tCO}_{2} /\right.$ toe $)$, which is smaller than that characterized by $\mathrm{CO}_{2}$ emissions in production in Serbia 3:14 ( $\mathrm{tCO}_{2} /$ toe $)$.

However, measured per capita the ratio in Serbia is smaller and equals $6.73\left(\mathrm{tCO}_{2} /\right.$ capita), while in the $\mathrm{EU}$ it is $7.92\left(\mathrm{tCO}_{2} /\right.$ capita). The emitted amount of $\mathrm{CO}_{2}$ observed in $\mathrm{CO}_{2} / \mathrm{GDP}$ is several times lower in the EU and amounts to 0.40 ( $\mathrm{kg} \mathrm{CO}_{2} / 2000$ USD), whereas in Serbia it goes to 3.78. In the end, the same indicator viewed through the purchasing power parity is $1: 03$ ( $\mathrm{kg} \mathrm{CO}_{2} / 2000$ USD) in Serbia, almost three times more than in the EU- 0:32 $\left(\mathrm{kg} \mathrm{CO}_{2} / 2000\right.$ USD), which indicates the purchasing power of Serbian population is weaker.

The numerical data from the tables speak in favor of the claim that economic development and environmental protection observed through general or composed indicators are not opposed. The results indicate that economic development is accompanied by improved energy efficiency, and vise versa.

\subsection{Comparison of Serbian and EU total energy supplies regarding energy sources}

Serbia is a country with specific features regarding the structure of primary energy, which must be taken into account when it comes to the adoption of certain attitudes and design of policies to increase energy efficiency, as a precondition for Serbia to participate in the carbon credits market. In order to gain insight into the real situation in this area, as in the previous case it was necessary and justified from the methodology aspect to analyze features of primary energy supply in Serbia in comparison with the EU.

In order to make the graphic display of the structure of primary energy in Serbia clear (Fig. 2), it is necessary to take into account the characteristics of its energy situation:

- The largest part of the geological reserves of all energy sources in Serbia makes coal with the participation of lignite of $85 \%$. Further investigations may increase the reserves by $20 \%$. Great

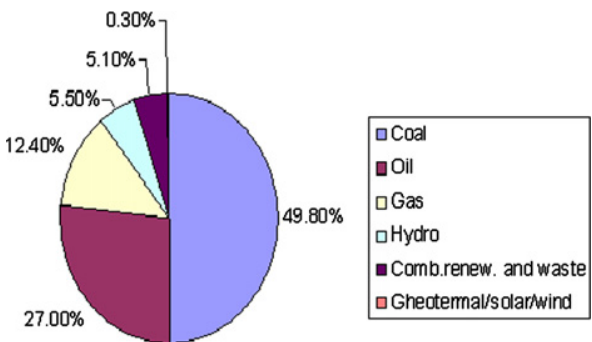

Fig. 2. Share of total primary energy supply in Serbia.

Source: http://www.iea.org/statist/index.htm, OECD/IEA 2009, date of extraction: 24 April 2010, 21:51 CEST.

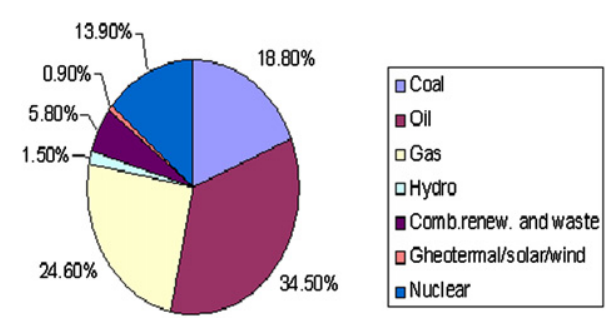

Fig. 3. Share of total primary energy supply in the EU.

Source: http://www.iea.org/statist/index.htm, OECD/IEA 2009, date of extraction: 24 April 2010, 21:51 CEST.

unused reserves of lignite are located in Kosovo, but cannot be used to produce energy for Serbian industry.

- Geological reserves of oil and gas are mainly exhausted, which makes Serbian economy dependent on energy imports.

- Known reserves of lignite and hydro potential in large water flows are already engaged in power plants in operation, and since the reserve in Kosovo are unavailable, the construction of new facilities and power plants is not likely.

General survey of the primary energy supply in Serbia is given in Fig. 2.

In Serbia, the dominant form of primary energy supply is coal with the relative share of almost $50 \%$, while the share in the EU is less than one-fifth of the total supply (Fig. 3). The participation of oil and gas in Serbia in the energy supply is a little higher than one-third. Other needs for primary energy are met by using the renewable sources: geothermal, solar and wind energy $(0.3 \%)$, and energy from waste and other combined renewable energy sources (5.1\%), but generally with a low participation (total 5.4\%).

The characteristics of primary energy supply in the EU show a somewhat different distribution as shown in Fig. 3.

The analysis of presented data provide a clear insight into the characteristics of primary energy supply in the EU, as well as into certain differences that exist with respect to data shown for Serbia. The participation of oil and gas in energy supply in the EU member states is very high and amounts to more than half of total energy sources. The share of renewable combined resources in the primary energy production in the EU is not high as well. In the case of geothermal, solar and wind energy, the percentage is less than $1 \%$ but is still three times higher compared to the same share of energy sources in Serbia. As for the other combined renewable energy sources and energy derived from waste, the EU also does not record a high percentage (5.8\%) in the total energy supply. On the other hand, Serbia in the production of energy has a high share of renewable hydro-energy (5.5\%), but as mentioned above additional exploitation of hydropotential is not possible in the near future. The share of hydropower usage at EU level is very low (1.5\%). In Serbia, there is no significant participation of energy 
production from nuclear sources, because there are no nuclear power plants on its territory, while the nuclear fuel share in the EU energy structure is even $13.9 \%$.

Consequently, it can be said that Serbia has scarce natural energy reserves, especially oil and gas, i.e. it is very dependent on energy imports. The existing energy reserves can only be used in small and medium power plants whose construction requires additional investments. On the long-term bases these investments would pay off because they would produce favorable economic effects, i.e. reducing of the costs of inputs in industry, distant district heating or in the distribution of produced energy.

\section{Proposal for measures to increase Serbian energy efficiency and carbon market access}

The rational use of energy and energy efficiency increase are important on the global scale because of the limited reserves of fossil fuels, global warming and the continued growth of energy consumption in spite of the Kyoto Protocol and other mechanisms trying to reduce the expenditure. By 2020, the EU wants to achieve the objectives set as 20/20/20, which applies to energy efficiency increase by $20 \%$, increase of the renewable sources participation in electricity generation by $20 \%$ and reduction of $\mathrm{CO}_{2}$ emissions by $20 \%$.

In Serbia, the rational use of energy sources is more a necessity than an alternative. This position requires strategic decisions and long-term plans regarding the optimal combination of fuels along with the urgent replacement of leaded fuel with unleaded. Energy efficiency is related to economic efficiency and includes changes in technological processes as well as in the structure of production processes. These changes can be carried out with a better and/or different organization of production processes and services. This leads to the conclusion that energy efficiency is not only a technical question but also the question of readiness of management to implement the changes on micro- and macrolevels. Being equipped with adequate technology, training of employees and management, and adequate organizational structure in the existing sectors of the energy system are vital for the introduction of changes. Energy efficiency has a much wider significance than technology efficiency of certain technological processes, equipment and devices because it must cover the entire economic system. Therefore, it is necessary to apply the Energy Development Strategy in Serbia, introduce new and implement existing laws, bylaws, regulations, measures and standards, and change the tax policy. As a result of the synergetic effect it is possible to achieve reducing of the amount of energy necessary to realize the unit of economic activity (energy required per unit of GDP) with the unchanged level of quality of life.

In the Energy Development Strategy of Serbia until 2015 the priority development programs are divided into three levels: basic, targeted and special priority [10]. Under the basic priority is meant the technological modernization of energy facilities. The targeted priority refers to the rational use of energy sources and energy efficiency. The special priority requires a longer time to implement because it refers to the use of renewable energybiomass, small hydropower plants, research and utilization of geothermal resources, and use of solar energy for heating.

The reasons for the failure of previous attempts to increase energy efficiency lie primarily in the lack of coordination concerning the Ministry of Energy, Ministry of Science and Technology and Ministry of Environment and Spatial Planning, and the lack of interest in other ministries responsible for agriculture, capital investments, economics and finance. Additionally, there is a discrepancy between the Government's Strategy of Economic Development and the Energy Efficiency Policy. Unfortunately, the program of implementation of Energy Development Strategy until 2015 is not accompanied by priority definition and the Plan of Realization, or by appropriate financial support. It is particularly difficult that the macroenvironment is in an unfavorable economic situation and that a large number of production facilities are not working at optimal levels or are not working at all. Further reasons of the failure include the absence of monitoring as regards capital and energy flows in the industry and utilities sector, which is the basis for the future work.

Potentials for increasing energy efficiency lie in the whole chain of energy transformations, from production through distribution to production consumption and final consumption in households:

- Reduction of imports of liquid and gaseous fuels-Serbia is highly dependent on imported energy, but such a move would lead to significant financial savings.

- Intensified use of domestic energy resources.

- More efficient use and modernization of existing energy facilities.

- Attracting of foreign investments, international projects, various forms of joint ventures that would result in the introduction of clean "green technologies", which would be advantages of the acceptance of the Kyoto mechanism.

- Emission reduction of $\mathrm{CO}, \mathrm{CO}_{2}, \mathrm{SO}_{2}, \mathrm{NO}_{x}$, and $\mathrm{GHG}$ and particles as residuals of the production processes, and participation in the carbon market.

- Stability in the supply of large consumers, which reduces their input costs and raise competitiveness in the global market.

- Updating of the Energy Development Strategy in line with the Kyoto Protocol by defining priorities, goals, and action plans with clear financial support.

- Definition of national (macro) priorities, needs of specific industries (meso-level) and population needs (micro-level).

- Establishing of the Energy Efficiency Fund.

- Introduction of mandatory monitoring and measurement of capital and energy flows in the industry with the tightening of inspection and control of energy facilities.

- Payment system based on thermal energy consumption.

- Creating of a supportive legal and financial environment for physical and legal persons who undertake activities to increase energy efficiency, use of domestic sources of energy, waste fuels and waste heat.

- Establishing of qualified, state-of-the-art attestation laboratories and encouraging of basic, applied and developmental research.

- Funding of research projects in the field of energy efficiency, and directing of scientific research to follow the objectives of the Energy Development Strategy and the Strategy and Policies of Energy Efficiency Increase.

- Funding of pilot and demonstration facilities and establishing of "best practice" funds.

- Promotion of positive examples with the call for more extensive use of such practice, etc.

All these measures and activities are the foundation for the realization of the long-term project to increase energy efficiency in Serbia, which will enable Serbia to appear on the carbon credit market and thus significantly improve its unfavorable economic situation.

\section{Conclusion}

The implementation of the Kyoto Protocol, as the most comprehensive international economic instrument of the United 
Nations for the protection of the environment and encouragement of sustainable economic development, provides great economic benefits to all countries especially the developing ones. The application of different mechanisms aiming to increase energy efficiency in Serbia could contribute to the increase in annual GDP growth rate of $5-7 \%$, which cannot be achieved by any other economic instrument. Consequently, the model economy vs. ecology is definitely an obsolete way of looking at economic growth.

The analysis of basic economic indicators of social wealth and energy efficiency indicators leads to the conclusion that the sustainable economic development of Serbia requires the increase in energy efficiency. Additionally, in Serbia only one-fifth of the annual consumption of oil and a quarter of gas consumption originate from domestic sources. With regard to energy sources, Serbia has significant deposits of coal, but these sources are mostly already engaged and will be spent during the working life of existing power plants. Therefore, suitable sources of energy in the near future may include the following: improved energy efficiency, use of biomass, exploitation of small underground coal mines, hydropower potential of small rivers, and intensive use of geothermal energy.

Serbian lack of energy efficiency can be converted to a comparative advantage through the participation in the global carbon market. Although each market carries risks, there are no risks in this market for developing countries unless the country invests in projects alone. Even in this case, the risk is limited to the loss of additional profits from emission credits, and cannot cause the loss of invested capital for the improvement of energy efficiency is a long-term investment rather than a cost. When someone else is investing on the basis of bilateral or multilateral agreements, the investor bears all the risk. So far, expected Serbian costs in the attempt to participate in the international carbon market are related to the organization of a competent administration that would approve projects meeting strict UN requirements of the Clean Development Mechanism.

There will be a range of positive effects in Serbia resulting from the growth of energy efficiency through the international carbon market: encouraging innovations in the economy, attracting new "green" technologies, improving international competitiveness, and support of long-term economic growth with the simultaneous application of the principles of sustainable development. Attracting investments into such projects provides the potential for the longterm growth of sustainable efficiency of economy, since companies become more profitable by reducing production costs while their outputs become more competitive in international markets.

What is also of great importance is a more pronounced sense of the popularity of those production processes that do not harm the living environment and help realize the sustainable development with economic benefits. Finally, with the implementation of the Kyoto Protocol Serbia would send to the international community and the EU a clear signal on readiness to apply the concept of sustainable development and global socioeconomic trends, which would improve its investment climate and confidence of potential foreign investors.

\section{References}

Energy Sector Development Strategy in Serbia until 2010 as part of Economic Development Strategy of Serbia until 2010, according to the decision of the Serbian Government in February 2001.

Gingrich, S., Kuškova, P., Steinberger, J.K., 2011. Long-term changes in $\mathrm{CO}_{2}$ emissions in Austria and Czechoslovakia-identifying the drivers of environmental pressures, Energy Policy 39 (2), 535-543.

Golušin, M., Munitlak Ivanović, O., 2009. Definition, characteristics and state of the indicators of sustainable development in countries of Southeastern Europe. Agriculture, Ecosystems and Environment 130, 67-74.

Golušin, M., Munitlak Ivanović, O., Bagarić, I., Vranješ, S., 2009. Exploitation of geothermal energy as a priority of sustainable energetic development in Serbia. Renewable and Sustainable Energy Reviews, 868-871.

Kovačić, Z., 2010. Energetska efikasnost u Srbiji nezadovoljavajuća, Agencija Tanjug, 04.03.2010 (Energy efficiency in Serbia is unsatisfactory, Tanjug Agency, 04/03/2010).

Kjoto protokol (Aneks B) i Izveštaj Regionalnog centra zaštite okoline za Srednju i Istočnu Evropu, Jul 1999, str. 67; Vukotić K, Opšti uslovi i vremenski okvir Kjoto mehanizama, Prvi simpozijum sa međunarodnim učešcem, Beograd; 2005, str. 206-210 (Kyoto Protocol, (Annex B) and Report of the Regional Environmental Center for Central and Eastern Europe, July 1999, p. 67; Vukotić, K., General terms and timeframe of the Kyoto mechanisms, The First Symposium with International Participation, Belgrade, 2005, pp. 206-210).

Mewton, R.T., Cacho, O.J., 2011. Green Power voluntary purchases: price elasticity and policy analysis. Energy Policy 39 (1), 377-385.

Munitlak Ivanović, O., 2005. Ecological aspects of sustainable developmentinternational and regional comparation. M.Sc., Ph.D. Thesis, Faculty of Economics, Subotica, Serbia.

Munitlak Ivanović, O., Golušin, M., Dodić, S., Dodić, J., 2009. Perspectives of sustainable development in countries of Southeastern Europe. Renewable and Sustainable Energy Reviews 12, 2079-2087.

Stambouli, A.M., in press. Algerian renewable energy assessment: the challenge of sustainability. Energy Policy doi:10.1016/j.enpol.2010.10.005. 